\title{
Heat Diffusion in Klinker Facade: The Study Case of a Gio Ponti Building
}

\author{
N. Ludwig, ${ }^{1}$ E. Rosina, ${ }^{2}$ S. Caglio, ${ }^{3}$ M. Gargano, ${ }^{1}$ and V. Redaelli ${ }^{3}$ \\ ${ }^{1}$ Department of Physics, University of Milan, via Celoria 16, 20133 Milano, Italy \\ ${ }^{2}$ B.E.S.T Department, Politechnic of Milan, via Bonardi 9, 20133 Milano, Italy \\ ${ }^{3}$ DERALAB srl, v. C. Correnti 14-20831 Seregno (MB), Italy
}

Correspondence should be addressed to E. Rosina, elisabetta.rosina@polimi.it

Received 18 August 2012; Revised 8 November 2012; Accepted 22 November 2012

Academic Editor: Marija Strojnik

Copyright (C) 2012 N. Ludwig et al. This is an open access article distributed under the Creative Commons Attribution License, which permits unrestricted use, distribution, and reproduction in any medium, provided the original work is properly cited.

\begin{abstract}
The researchers focus on the IRT procedure of heat diffusion in ceramic finishing materials of contemporary architecture. The aim of the research is the development of a method for the thermal characterization of clinkers, a very common ceramic finishing material of buildings. The first experimental phase was performed in laboratory on clinkers of different shapes, thickness, colors, and glazing surface. The researchers determined two characteristic parameters related to thickness and thermal conductivity, by the interpolation of the heating curve in function of time with an analytical curve (resulted from a particular solution of Fourier's equation). This curve allows to obtain a parameter characteristic of the material of the specimens under investigation. At present time, the researchers have been studying the correlation between this parameter and the damage level in the specimens; they will be testing the model on real-scale study cases in the second experimental phase.
\end{abstract}

\section{Introduction}

The use of clinker tiles for finishing the facades of contemporary architecture has been a common practice since the 50-60s.

The durability of the ceramic materials, their low cost, their stainless and apparently low sensitivity to pollution effects, and finally the low requirement for maintenance are some of the reasons of their diffused application in the Middle-Southern region of Europe, as an effective alternative to brick-faced masonry, timber cladding, and stucco.

After more than 50 years from its first use, most of the ceramic finishing shows damage due to weathering/pollution in the mortar joints and the mortar underneath the tiles [1-3] that cause the tiles detachment.

Since 2010, an articulate and widespread research has been developed at Politecnico of Milano and State University of Milan, entitled "Sustainable Campus Leonardo." The focus of the research is to involve scientists on the study, analysis, survey, assessment, management, repair, and enhancement of the universities' campus in the Eastern area of Milano.
Among these research lines, the authors developed a methodology to asses the state of conservation of the facades, especially ceramic finishing. In the present paper, the authors show the improvement of the preliminary tests based on the solution of the mathematical model of heat transfer in the ceramic medium. The preliminary test had its validation by softly hammering both the sound zone and the delaminated areas of the finishing. The different sounds revealed the detachment of the finishing. The method has been applied on historical buildings, dating back to the beginning of XX century up to the 60's. The more recent buildings, built with contemporary techniques and materials, were designed by one of the most famous architect of that time, Gio' Ponti, and they are included in the preservation office list of monuments (Figure 1).

Therefore, the assessment of facade in Campus Leonardo is an important issue both for economical aspects related to the costs of maintenance and for the project of repair, dealing with high historical and artistic valued contemporary buildings. From this side, the critical point is to preserve the authenticity of a building, of which materials 
could be perfectly replaced with new ones, thanks to the possibility of reproducing industrial tiles (and the other elements).

It is unanimously accepted in the current debate on restoration of historical building that the repair should be clearly identified, although it should not affect the aesthetical unit of the work of art, and that a mimetic solution, with the substitution of materials and elements with new ones à l'identique, has been a banned practice starting from the third decade of the XX century. Nevertheless, the common practice is to replace the damaged parts with new elements that have the same apparel of the original ones. As an example, the recent renovation of the historical site of Bauhaus, where the architects provided a consistent refurbishment, including the substitution of the finishing [4]. This approach could not have been applied in Campus Leonardo on Gio' Ponti buildings, because the architect designed special polyhedral tiles for his buildings, and he applied the tiles with different orientation to create different effects of reflection/color during the day, depending on the inclination of sun rays hitting the surface. The design of the surface is completely connected with the concept design of the building, in a holistic view of the buildings and its technological elements. His projects and realizations are yet innovative, because the architect always followed his incredible interest for experimentation in new materials and pattern. Therefore, the most advanced approach indicates the need to limit as much as possible any substitution, preventing the damage by reducing risk factors (environment, wrong building repairs, inadequate use, lack of maintenance, etc.) and by means of a plan of conservation [5].

The durability of the facade of contemporary buildings is also an important issue for managing the building sector, as well as the identification of the risk factors and the evaluation of the buildings' technological components' life cycle [6-8]; the costs of fixing the ceramic finishing is a large part of the economic effort within the whole maintenance predictable costs. Nevertheless, only few nondestructive tests are available to assess the facades, most of these tests require the contact with the surface under investigation (knocking with a hammer or knuckles or the vibration test $[9,10])$. Infrared thermography (IRT) is the only technique that ensures a no-contact investigation of the surface, and it has no competitor regarding costs (no scaffolding or forklift basket is required) or speed of inspection. Moreover, the expected results are a map that localizes and gives an approximated evaluation of the delaminated finishing's size.

Up to now, the common approach is the use of qualitative IRT allowing only an approximated mapping of defects and an evaluation of their size. False alerts in IRT are often the worst risk for the assessment, caused by the optical properties of tiles (colors, reflectance, and damage of the glazing surface), their geometric shape (i.e., Gio' Ponti designed polyhedral tiles, Figure 2, to enhance the effect of reflected light), the nonhomogeneous layer of mortar underneath, and the effects of aging [11].

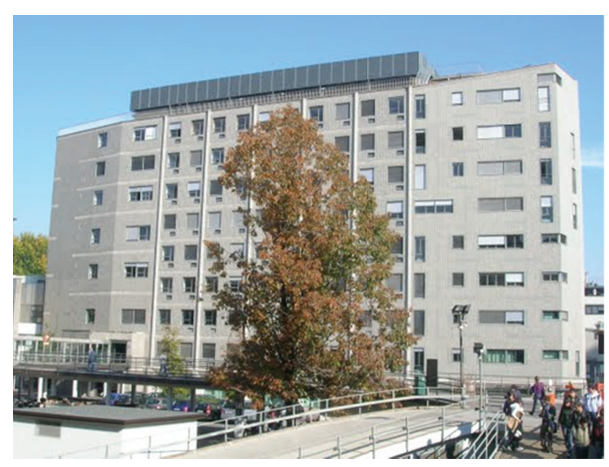

Figure 1: Gio' Ponti's building, La Nave, located in Milan, in Campus Leonardo, after restoration. Clinker finishing is better shown in Figure 3 that recaptures a small area of the Northern façade.

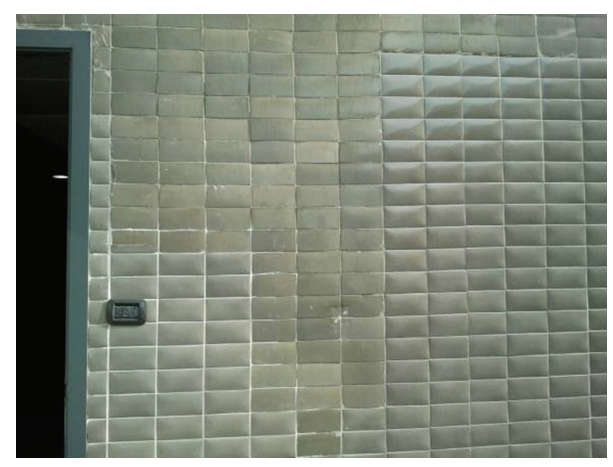

Figure 2: The two series of La Nave tiles after a first repair and substitution. Original tiles are on the right and the lower part of the left corner; the new tiles are on the upper/middle of left part of the wall.

However, to increase the reliability of the investigation, a new approach is necessary. If investigation is supposed to be an enhancement for the program of conservation and maintenance, the assessment of the facade has to be done in the very preliminary phase of the project, by noncontact tests and without any verification at close distance (from the scaffolding) therefore, it is necessary to increase the reliability of the tests results, because up to now the results of IRT application can be misleading $[12,13]$.

Simplified mathematical models that are able to describe with good approximation the thermal behavior of sound and defected surface can be useful to this aim [14-16].

Scientific literature on the properties of ceramic materials is very poor $[17,18]$, and none of the listed properties deals with the on-site thermal characterization and detachment analysis.

Authors determined two characteristic parameters related to thickness and thermal conductivity of the tiles, by interpolating the time-dependent heating curve with a analytical expression, deducted from a solution of Fourier's heat diffusion equation [15]. In the first part of the work, a standard procedures was used in the laboratory to obtain the thermal characteristics of selected ceramic specimens. 


\section{Determination of the Function of Surface Heating}

To determine the function that describes the surface heating of a wall, we have to consider the Fourier equation for the heat diffusion through a homogenous bulk

$$
\nabla^{2} T=\frac{1}{\alpha} \frac{\partial T}{\partial t}
$$

where $\alpha$ is the thermal diffusivity. In laboratory tests, it is assumed that the heat propagation in the sample is one dimensional, namely, taking place only along one direction $(z)$, specifically the perpendicular one to the face hit by the solar irradiation.

The experimental results are in agreement with this approximation, allowing us to apply it to real cases of study. The researchers chose the heating by irradiation simulated in the laboratory by a pair of halogen lamps and generated by the sun during on-site investigations.

Called $z$ the heat propagating dimension, the Fourier equation reduces to the following:

$$
\frac{\partial^{2} T(z, t)}{\partial z^{2}}=\frac{1}{\alpha} \frac{\partial T(z, t)}{\partial t} .
$$

The independence of the spatial variable $(z)$ by the time $(t)$ allowed the researchers to apply the method of separation of variables, so we have two coupled equations, one for the spatial variable $z$, named $\theta_{z}$, and one for the time $t, \theta_{t}$ :

$$
\begin{gathered}
\frac{1}{\vartheta_{z}} \frac{\partial^{2} \vartheta_{z}}{\partial z^{2}}=\lambda^{2}, \\
\frac{1}{\alpha \vartheta_{t}} \frac{\partial \vartheta_{t}}{\partial t}=\lambda^{2},
\end{gathered}
$$

where $\lambda$ is the unknown coupling term.

Seeking the function that describes the temporal evolution of the surface temperature of the wall, $z=0$ was set, and it was calculated the constants using boundary conditions deduced from the experimental curves, obtaining from the general solutions:

$$
T_{0}(t)=-\Delta T e^{-\lambda^{2} \alpha t}+T_{\mathrm{Max}}
$$

where $T_{0}$ is the surface temperature and $T_{\max }=T_{0}(t=\infty)$.

To determine the coupling parameter $\lambda$, the researchers used dimensional analysis, obtaining a relationship with a length $L$ that has been called limit of dimming. Where $\lambda=L^{-1}$ in $\left[\mathrm{m}^{-1}\right]$. The researchers defined the parameter $L$ by means of experimental tests in the laboratory of heat diffusion in the materials. $L$ depends on the material thermal characteristics, and it is the distance from the surface layer to the inner layer from which no thermal signal can be detected. It is not possible to detect any structure or void underneath the layer at depth $\geq L$ from the surface. $L$ depends on the kind and intensity of heating too, therefore the quantitative comparison between sound and detached areas has to be done at the same environmental conditions. In the case

\begin{tabular}{|c|c|c|}
\hline Board & Clinker & Emissivity \\
\hline - & K2 & 0.96 \\
\hline - & K4 & 0.94 \\
\hline - & K6 & 0.92 \\
\hline \multirow{6}{*}{ CE004 } & A1 & 0.98 \\
\hline & $\mathrm{A} 2$ & 0.98 \\
\hline & A3 & 0.98 \\
\hline & B1 & 0.95 \\
\hline & B2 & 0.95 \\
\hline & B3 & 0.95 \\
\hline \multirow{6}{*}{ CE7 } & A & 0.93 \\
\hline & B & 0.87 \\
\hline & $\mathrm{C}$ & 0.94 \\
\hline & $\mathrm{D}$ & 0.96 \\
\hline & E & 0.97 \\
\hline & $\mathrm{F}$ & 0.95 \\
\hline \multirow{6}{*}{ CE007 } & A & 0.96 \\
\hline & B & 0.94 \\
\hline & C & 0.89 \\
\hline & $\mathrm{D}$ & 0.96 \\
\hline & $\mathrm{E}$ & 0.96 \\
\hline & $\mathrm{F}$ & 0.97 \\
\hline \multirow{5}{*}{ CE008 } & A & 0.96 \\
\hline & B & 0.90 \\
\hline & $\mathrm{C}$ & 0.92 \\
\hline & $\mathrm{D}$ & 0.93 \\
\hline & $\mathrm{E}$ & 0.97 \\
\hline
\end{tabular}
studies of clinker detachments, this parameter is used to infer the presence of thermal anomalies due to degradation.
TABLe 1: Values of mean emissivity of the samples, tested in the laboratory.

\section{Laboratory Test}

23 clinker specimens, with different shape and colors have been studied for the evaluation of heat transmission and emission. Three tiles were simply laid plain; other three were applied on brick solid masonries, simulating a detachment between the tile and the masonry for half of the specimens surfaces. The other 17 specimens were glued to some plywood tables, and a scheme of the experimental setup is in Figure 3. The experimental setup for the heat transmission evaluation allowed to obtain an extremely homogeneous and controlled increase of the temperature up to $80^{\circ} \mathrm{C}$ on one side of the tile (front), by using on the rear a heating surface controlled through hot water vapor flux. The first evaluation had the purpose to measure the heating differences on the sound and delaminated areas of the same specimens, therefore, to simulate a real case of damaged areas.

Emissivity measurement was obtained by the comparison with a target of known emissivity (black carbon powder) by lighting of both the specimens and the target with two halogen lamps $(650 \mathrm{~W})$ symmetrically placed at $1.5 \mathrm{~m}$ from the objects. Measurements were obtained by a LW camera (microbolometric sensor, $0.08^{\circ} \mathrm{C}$ thermal resolution at $20^{\circ} \mathrm{C}$ ). Results of laboratory tests (Table 1 ) were used for 


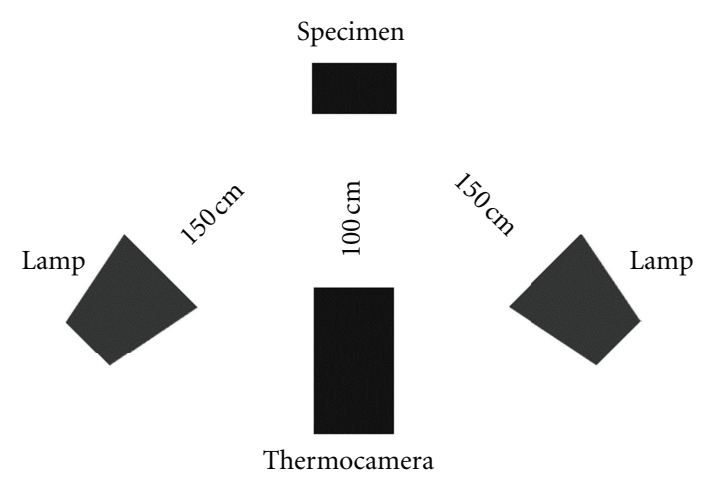

Figure 3: Plan of the experimental set-up in the laboratory.

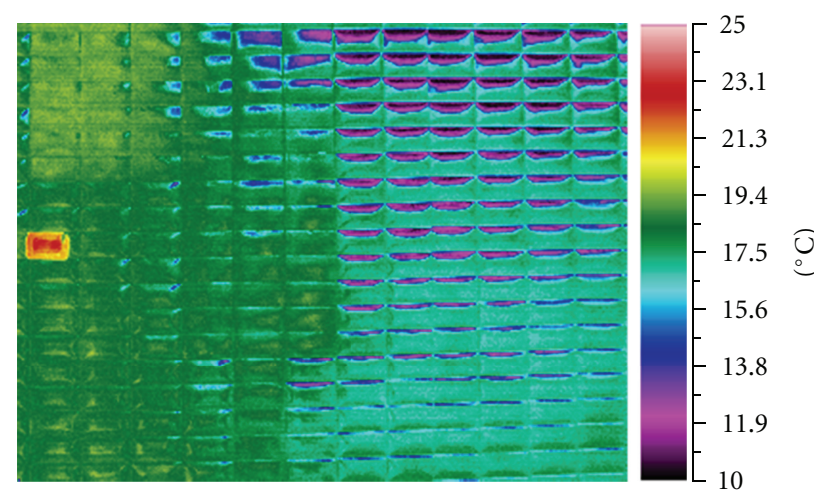

FIGURE 4: Infrared image of La Nave tiles. The recaptured area has a visualization in the visible range in Figure 2.

emissivity estimation in all on-site measurements, where emissivity values were unknown.

The experimental results of the laboratory tests give a 0.95 average value of emissivity. Values of emissivity distribution are shown in Figure 6. In the cases under study, the temperature variations, due to the differences of the emissivity values and those linked to the surface irregularities and colors, resulted smaller than the instrumental and experimental error, in particular, when the thermal gradient is taken into account instead of the temperature's absolute values.

Temperature differences between sound and damaged areas resulted to be $1-1.5^{\circ} \mathrm{C}$. As for the detection of detachments on plaster [14], the analysis of the thermal maps allows to find out the detachment of tiles. As an example of laboratory tests, Figure 7 shows the higher heating in the detached areas (the red dotted curve) due to the air gap underneath the tiles, as it happens for plaster and plaster detachments. The following tests were set on site with the aim to verify the real feasibility of the procedure on the real study cases.

\section{On-Site Tests}

The researchers chose a real-scale study case to examine the modalities of on-site monitoring and to test the laboratory procedure. A cavity wall of La Nave, an historical building at

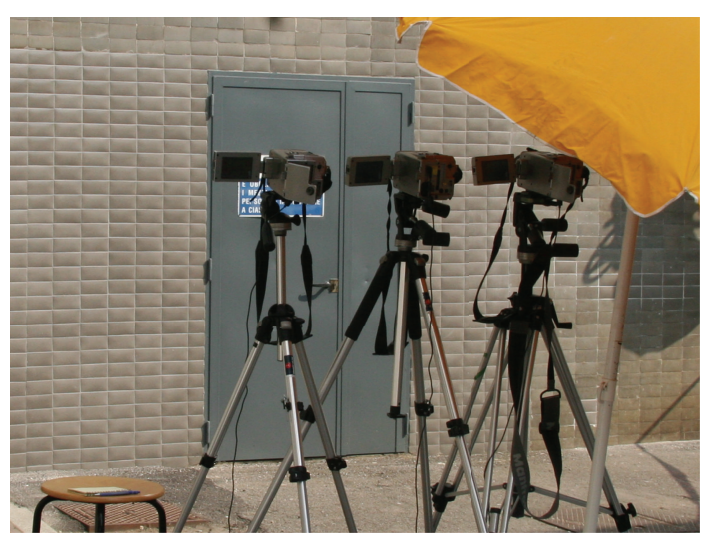

Figure 5: Experimental setup, three infrared camera, mod. TVS 700 .

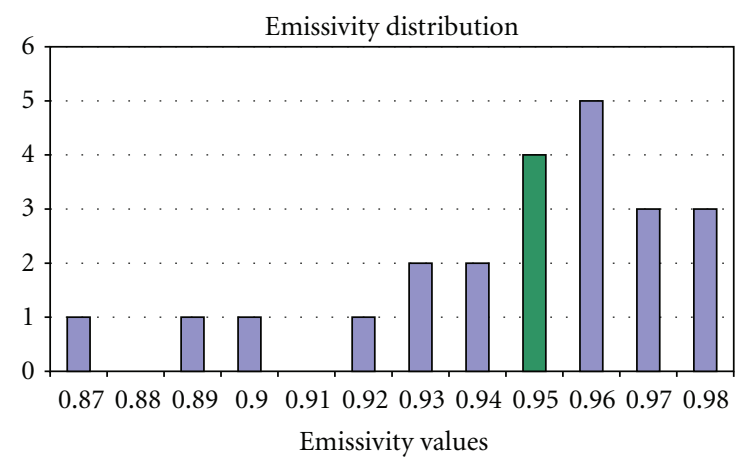

FIGURE 6: Emissivity distribution of samples based on the experimental recurrences.

Leonardo Campus, Politecnico di Milano (Figure 1), served as a mock up ( $L a$ Nave is a Gio Ponti's listed building; it recently underwent restoration of the facades due to the clinker tiles detachment). The wall has a solid concrete structure of $8 \mathrm{~cm}$ thick, an interior cavity of $23 \mathrm{~cm}$, a finishing of mortar $(2.5 \mathrm{~cm}$ thick), and grey clinker tiles $(3 \mathrm{~mm})$. The examined side of the wall is the Southern elevation, ground level. Southern orientation was chosen with the aim to exploit the solar irradiation and obtain a relevant thermal gradient for the following data processing and analysis. Measurements were performed in reflection mode, in two consecutive days, with clear sky and similar environment temperature (air temperature ranging between 15 and $24^{\circ} \mathrm{C}$; RH 40-64\%), in the same location. Three thermocameras (TVS Avio $700 \mathrm{LW}$, the same model used in the laboratory tests) recorded a sequence of 420 images each, at the rate of 1 frame per minute, during 5 hours of sun irradiation and 2 hours of cooling, for the purpose to investigate a wide surface at the same natural heating conditions. The recaptured images have a spatial resolution of few $\mathrm{mm}$, which is necessary to detect the mortar joints between the tiles. Furthermore, the use of three thermocameras allowed the researchers to study the effects of different angles of view and solar irradiation on nonplanar surfaces. In particular, the test area on La Nave wall surface shows the presence of both Gio' 


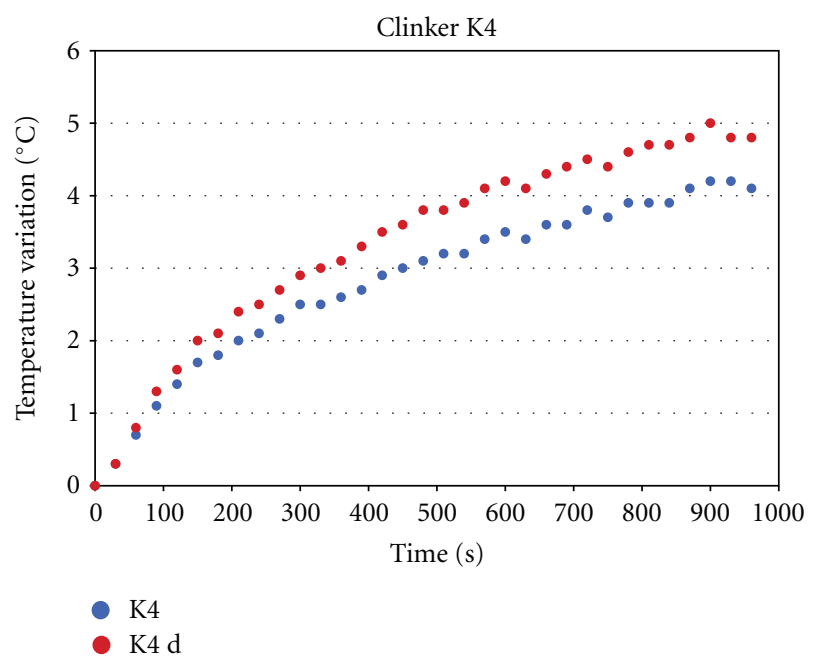

FIGURE 7: Heating of a sound area (K4) and delaminated one (K4 d) in clinker tile K4.

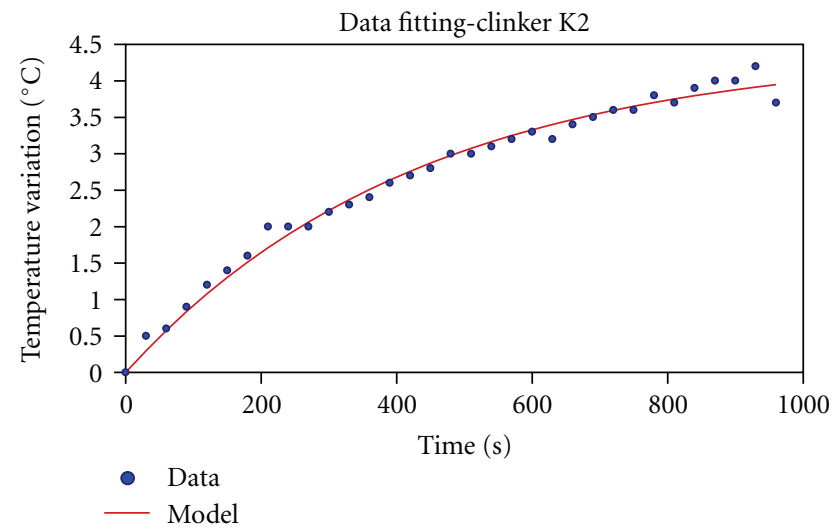

FIGURE 8: Fitting of the heating data obtained in the laboratory test with the mathematical model for K2 clinker. $R^{2}=0.989$.

Ponti tiles and new tiles, due to maintenance intervention. The new series of tiles have flat and smoother surface while the original ones have rounded polyhedral surface (Figure 2). All the tiles have similar grey colors therefore, it was possible to avoid the effects of the absorption of solar radiation due to the colors in the analysis of the heating curves.

The selected area under investigation has been analyzed by means of three thermocameras, set at $4.5 \mathrm{~m}$ from the surface, recapturing different areas of $2 \mathrm{sq} \mathrm{m}$ at $1.5-3 \mathrm{~m}$ from the ground level (Figure 5).

The thermocameras started the shooting $30 \mathrm{~min}$ before the direct solar irradiation and continued 1 hour after the shadowing, for a total time 7 hours, with a rate of 1 frame per minute. The first day, the lens axis of the three thermocameras was set perpendicularly to the surface (Figure 4).

The second day, the researchers set the lens axis with different inclination, with the aim to verify the influence on the measures of the inclination as an effect of the reflection of the solar irradiation on the tiles.

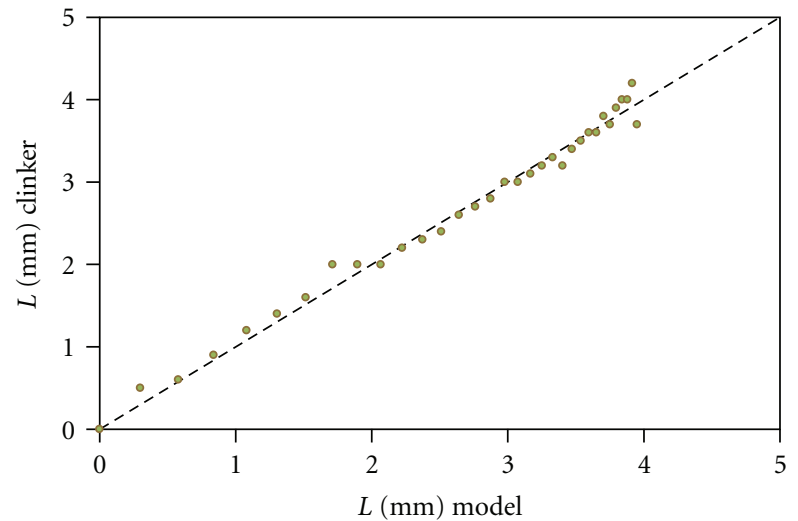

FIGURE 9: The relation between the calculated values and the experimental ones shows a close match in laboratory tests, $R^{2}=$ 0.989 .

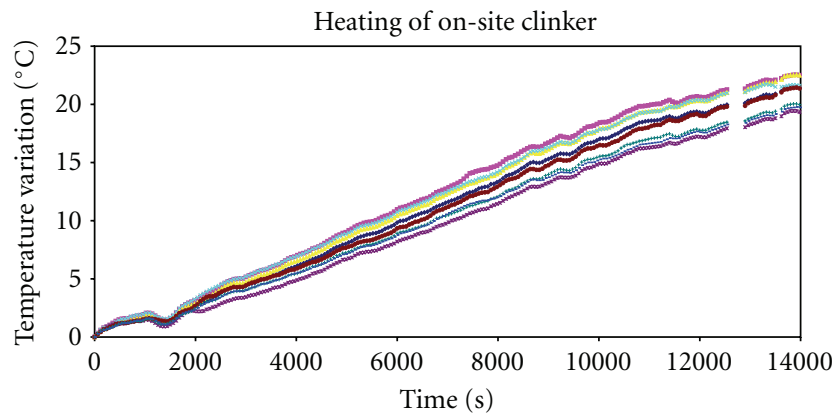

FIGURE 10: Experimental results of the on-site recaptures: the trend of the areas is similar and the differences of temperatures of the heating are very small at the end $\left(<5^{\circ} \mathrm{C}\right)$.

\section{On-Site Test: Data Analysis and Results}

The data acquired on the second day showed a different thermal response on the rounded surface of tiles due to the shooting angle. The thermal analysis of the tiles with flat surface showed small differences when varying the shooting angle. Nevertheless, in the analysis of thermal gradient, the effect of the inclination of the recapture axis, and therefore of the reflected radiation, are negligible for such small differences.

A general suggested procedure is to capture the areas with different viewing angles, better if symmetrical.

As expected, the derived curves obtained by the laboratory tests (Figures 8, 9, and 10) fit better the mathematical model than the results of on-site tests. Errors of temperature evaluation have the same magnitude of incertitude of the thermocameras sensors $\left(0.08^{\circ} \mathrm{C}\right)$. This is due to the higher irradiation necessary to heat the whole surface; in fact, the wall did not reach the equilibrium with the environment even after 5 hours of solar irradiation. On the contrary, during the laboratory tests, this steady condition was achieved after only 20 minutes of irradiation by halogen lamps.

Up to now, the researchers are acquiring new data on clinkers with different colors laid on concrete and stucco, 
with the purpose to verify and extend the recording and analysis procedure.

Moreover, the authors are looking for relations between the parameters and the level of damage of the surface.

\section{Conclusions}

The results pinpoint that the IRT application study detecting delaminations of clinker finishing is similar to the wellknown application of the investigation of stucco and plaster finishing, although tiles have a nonplanar, irregular, and reflective surface. The development of both an experimental methodology for homogenous heating of the samples and a data interpolation curve allowed to obtain two parameters characteristic of clinker tiles' thermal behavior in laboratory studies/tests. Experimental data fit with the function expressing the law of heat diffusion. The semiquantitative approach used in the definition of the damage level of the investigated areas is a novelty that can bring interesting results on real-scale experiments. At present, the researchers are testing the feasibility of the procedures on site, in addition to the verification of the calculation procedure that are so far robust and fitting of the experimental data. A further development is to reduce the amount of thermographic shootings necessary to extract the fitting parameters.

\section{References}

[1] F. Re Cecconi, Metodologie e strumentazioni per la previsione della durabilità di componenti edilizi per edifici scolastici ai fini della loro programmazione manutentiva [Ph.D. thesis], 1996.

[2] S. M. Cornick and M. A. Lacasse, "An investigation of climate loads on building façades for selected locations in the United States," Journal of ASTM International, vol. 6, no. 2, pp. 1-17, 2009.

[3] R. Mačiulaitis, A. Kičaite, D. Nagrockiene, and G. Kudabiene, "Evaluation of service frost resistance of ceramic facing tiles," Journal of Civil Engineering and Management, vol. 10, no. 4, pp. 285-293, 2004.

[4] M. Markgraf, "Conservation and preservation of the bauhaus building in Dessau," IV. World Heritage Sites of the 20th Century-German Case Studies, pp. 108-111, 2006.

[5] A. Canziani, On the Edge of Modern Heritage Conservation (Conservare L'Architettura), Electa, Milano, Italy, 2009.

[6] M. K. Kumaran, P. Mukhopadhyaya, S. M. Cornick et al., "An Integrated methodology to develop moisture management strategies for exterior wall systems," in Proceedings of the 9th Canadian Conference on Building Science and Technology, pp. 45-62, Vancouver, Canada, 2003.

[7] H. Künzel, H. M. Künzel, and K. Sedlbauer, "Long-term performance of External Thermal Insulation Systems (ETICS)," ACTA Architectura, vol. 5, no. 1, pp. 11-24, 2006.

[8] B. Daniotti, S. Lupica Spagnolo, and R. Paolini, "Climatic data analysis to define accelerated ageing for reference service life evaluation," in Proceedings of the 11th Conference on Durability of Building Materials and Components (DBMC '08), Istanbul, Turkey, 2008.

[9] E. Esposito, S. Copparoni, and B. Naticchia, "Recent progress in diagnostics of civil structures by laser vibrometry," in Proceedings of the 16th World Conference on Nondestructive Testing, Montreal, Canada, 2004.
[10] P. Castellini, E. Esposito, B. Marchetti, E. Esposito, and E. P. Tomasini, "New applications of Scanning Laser Doppler Vibrometry (SLDV) to non-destructive diagnostics of artworks: mosaics, ceramics, inlaid wood and easel painting," Journal of Cultural Heritage, vol. 4, supplement 1, pp. 321-329, 2003.

[11] M. A. Crippa, A. del Conte, E. Esposito, and P. Perrotta, "Applicazione di sistemi ottici per la Diagnostica dello stato di adesione di Rivestimenti superficiali: il caso dell'edificio "Trifoglio" del Politecnico di Milano," in Atti del 11th Conferenza Nazionale sulle Prove non Distruttive Monitoraggio Diagnostica e 11th Congresso Nazionale dell'AIPnD, Milan, Italy, 2005.

[12] E. Edis, I. Flores-Colen, and J. De Brito, "Passive thermography inspection of adhered ceramic claddings: limitation and conditioning factors," Journal of Performance of Constructed Facilities, pp. 258-268, 2012.

[13] S. Striato, Edificio 14 al Politecnico di Milano:indagini per la conservazione della compaggine muraria [Dissertation thesis], Politecnico di Milano, AA, 2011/2012.

[14] N. Ludwig, "Thermographic testing on buildings using a simplified heat transfer model," Materials Evaluation, vol. 61, no. 5, pp. 599-603, 2003.

[15] S. Caglio, Tecniche di termografia dinamica per lo studio di fenomeni di diffusione del calore in materiali di interesse archeometrico [M.S. thesis], faculty of Physics, State University of Milan, 2004/2005.

[16] N. Ludwig and P. Teruzzi, "Heat losses and 3D diffusion phenomena for defect sizing procedures in video pulse thermography," Infrared Physics and Technology, vol. 43, no. 3-5, pp. 297-301, 2002.

[17] D. Muez and T. Fett, Ceramics, Mechanical Properties, Failure Behaviour, Materials Selection, Springer, Berlin, Germany, 1999.

[18] J. Stránsky, J. Vorel, J. Zeman, and M. Šejnoha, "Mori-Tanaka based estimates of effective thermal conductivity of various Engineering materials," Micromachines, vol. 2, no. 2, pp. 129149, 2011. 

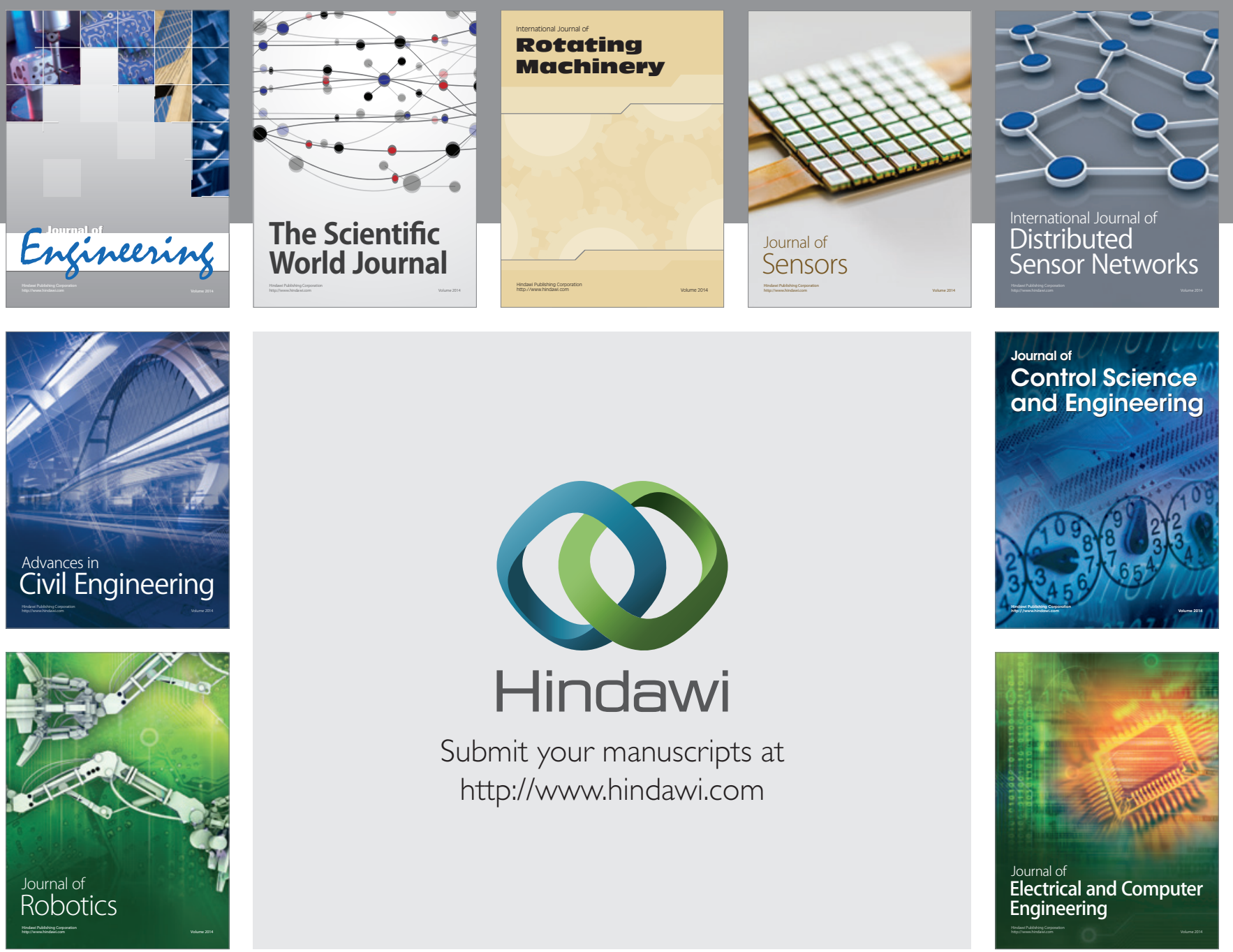

Submit your manuscripts at

http://www.hindawi.com
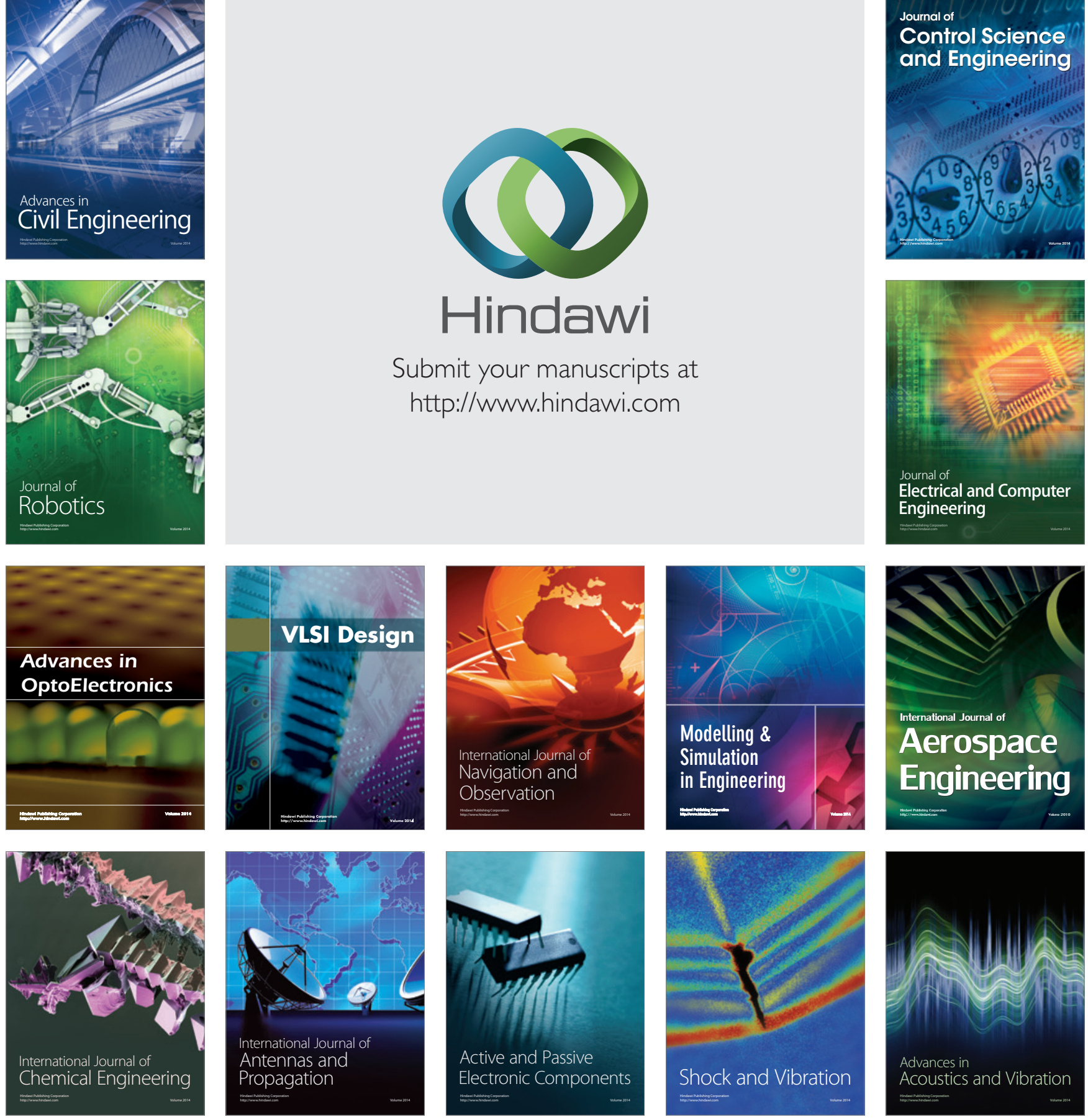